\title{
The Worst and the Best of Propaganda
}

\author{
Bianca Cepollaro ${ }^{1}$ \\ Vita-Salute San Raffaele University, Milan
}

Giuliano Torrengo

University of Milan

DOI: $10.2478 /$ disp-2018-0006

BIBLID [0873-626X (2018) 51; pp.289-303]

\begin{abstract}
In this paper we discuss two issues addressed by Jason Stanley in How Propaganda Works: the status of slurs (Section 1) and the notion of positive propaganda (Section 2). In particular, in Section 1 we argue contra Stanley that code words like 'welfare' are crucially different from slurs in that the association between the lexical item and an additional social meaning is not as systematic as it is for slurs. In this sense, slurs bring about a special kind of propagandistic effect, even if it typically concerns informal contexts rather than public debates. In Section 2, we consider positive propaganda and its relation to emotional effects. For Stanley, positive propaganda relies on the production of emotional effects, feature which risks to erode rational debates even if there is a good purpose behind. Instead, we argue that positive propaganda can work with no appeal to emotions. To this end, we focus on the use of 'she' as the default personal pronoun in academic writing and suggest that this measure can count as positive propaganda which rather than eroding rational debates by relying on emotional effects, closely resembles affirmative action aimed at counterbalancing a pre-existing form of injustice and inequality.
\end{abstract}

\section{Keywords}

Slurs, How Propaganda Works, code words, positive propaganda, affirmative action

\footnotetext{
${ }^{1}$ Bianca Cepollaro mostly contributed to Section 1, Giuliano Torrengo mostly contributed to Section 2. 
In How Propaganda Works, Jason Stanley sets the ambitious objective of providing a complete explanation of the mechanisms and effects of propaganda. The kernel of Stanley's analysis is the following. In societies characterized by inequalities, people typically developed self-justifying ideologies, 'legitimizing myths' aimed to mask inequalities. Flawed ideologies (false beliefs that are resistant to available evidence) are a condition for propaganda to catch on. The reason why propaganda is so dangerous to liberal democracies is that it prevents fair deliberation and equal participation, which are the basis of democracy. Stanley discusses different types of propaganda and flawed ideologies, although his investigation mainly focuses on the most threatening type of propaganda: 'undermining demagoguery', a contribution to public discourse that presents itself as in the service of a worthy ideal, while in fact undermining that very ideal. Among the many merits of this work is the fact that Stanley often illustrates the theoretical distinctions he introduces by drawing on a rich set of concrete situations and current topics in the political debate: from the climate change debate to the 2003 war in Iraq, to the reforms of American education etc. The whole book has a remarkable interdisciplinary stance, as it assesses the most central questions in political philosophy, while resting on an analytic background. Moreover, it has the uncommon merit of systematically presenting and discussing the work of scholars in philosophy, sociology and linguistics from underrepresented groups.

In this paper, we will not go through the main arguments of the book. Rather, we will discuss two issues that interested us for independent reasons: the status of slurs, on the one hand (Section 1), and the notion of positive propaganda, on the other hand (Section 2). First we will focus our attention on the fourth chapter, the one dedicated to language mechanisms, and then turn to the third chapter, where the notion of 'positive propaganda' is assessed. Other parts will be touched upon only tangentially.

\section{Slurs are special after all}

In chapter four, Stanley presents his account of how certain terms can serve as propagandistic tools in liberal democracies. Apparently innocuous terms that are accepted in discourse and present them- 
selves as 'reasonable' (that is, respectful of the perspective of each of the parties involved, 94) acquire an additional meaning that is politically and socially charged and that can erode reasonableness. Stanley's example is 'welfare': its at-issue meaning corresponds to something like 'social assistance from the government'; in addition, it also conveys a not-at-issue meaning. This consists both of a certain racist content (something along the lines of 'black people are lazy', as the term 'welfare' is often associated with the flawed assumption that black people abuse social assistance) and also of a preference ordering over worlds in the linguistic context, according to which for any black person in the States, worlds in which that person is lazy are closer than worlds in which she is not (144-45). Expressions such as 'welfare' acquire new contents by a mechanism of repeated association between words and social meanings (138). This additional content gets to be part of the conventional meaning of the term and it is typically not-at-issue (therefore, it cannot be directly challenged or denied). According to Stanley, slurs work in the same way as expressions such as 'welfare'. For Stanley a word like 'kike' has 'Jewish' as at-issue meaning and it has a not-at-issue meaning that consists both of a certain pejorative content (something like 'Jewish people are greedy') and of an imposed preference ordering for which for any given Jewish person, possible situations in which she is greedy are closer than ones in which she is not (146).

In this section, we are particularly interested in Stanley's treatment of slurs and we will focus on three of his claims: (i) 'the focus philosophers have placed on explicit slurs is misplaced' (155); (ii) 'slurs are not special' (150) and (iii) 'words like 'kike' have not-atissue meanings' (146). We will claim that in order to maintain (iii), (ii) — and possibly (i) — should be dropped.

Let us start from the first point, one that does not strictly concern slurs, but the debate on slurs. Linguists and philosophers in the last years have devoted their attention to these expressions. Some accounts of slurs (Camp 2013 for instance) put emphasis on the propagandistic power of slurs, that is, on the idea that slurs do not only reflect discriminatory attitudes but they are also able to propagate them. For Stanley, the attention devoted to slurs is misplaced because propagandistic power is not a distinctive feature of slurs and in fact slurs might even lack any such property. Stanley's point is that 
slurs are so explicitly racist that they could not do any real propaganda, nor do they typically occur in public political debates, at least in liberal democracies. As a matter of fact, politicians constantly seek terms and expressions that are able to convey politically/socially charged additional contents — as slurs do — while being acceptable in public discourse. Stanley calls these terms 'code words'. The term 'welfare' is such an example: it presents itself as reasonable (as it simply refers to social assistance), but its 'social meaning' (see Haslanger 2013) actually erodes reasonableness as it amounts to something like 'black people are lazy'. These code words can be really harmful in liberal democracies as, unlike slurs, they are permissible. Therefore, according to Stanley, scholars should investigate these code words rather than focusing on slurs.

These remarks on the investigation on slurs might be too hasty and they may overlook a couple of points. For one thing, even though nowadays in liberal democracies slurs are banned from public political discourse, they are anyway used in many other contexts, that are not less apt to shape one's political view than public discourses. Indeed, Stanley himself notices that it may be a sign that a liberal democracy is fading if slurs become more acceptable also in political discourse (his example is from Hungary, 151), thereby suggesting that the presence of slurs in ordinary contexts is not irrelevant for political discourse either. When scholars talk about the propagandistic power of slurs (even within liberal democracies), they refer to the private settings where slurs are in fact employed and such settings are just as effective as public debates in shaping one's political views. As Stanley himself acknowledges 'Citizens gather to speak about politics in all sorts of informal settings (...) [that] guide us in our political choices' (88). Moreover, even though the use of a slur is explicitly racist in the sense of being patently racist, the pejorative content of slurs is analyzed by many authors ${ }^{2}$ (including Stanley) as notat-issue. Even though the discriminatory content conveyed by slurs is not implicit ${ }^{3}$ in the same sense in which some racist content is implicit when politicians talk about 'work ethic' while tacitly alluding

${ }^{2}$ For example, Potts 2005, 2007, McCready 2010, Cepollaro and Stojanovic 2016.

${ }^{3}$ About the explicit/implicit distinction, see i.a. Bach 1994 and Carston 2002. For a discussion about how implicit communication relates to ideology see Sbisà 1999. 
to the assumption that black people are lazy, the not-at-issue status of the pejorative content of slurs determines particular features of nonnegotiability that have something in common with those of implicit allusions or suggestions. In other terms, both the not-at-issue content of code words in political discourse and the not-at issue content of slurs in informal settings are not presented as open to discussion, and if the former phenomenon is central to the mechanism of propagandistic speech, the latter is to the formation of prejudicial stances towards target groups, which seems to be an essential background condition for propaganda to work. As a matter of fact, a well-known feature of the pejorative content of slurs, presented and discussed by Stanley (148), is that it survives under semantic embeddings and it cannot be negated via denial. Observe:

(1) If Jason's parents are wops, he must be stylish.

(2) A: Is Jason a wop?

B: No, he isn't.

Even though 'wop' is embedded in the antecedent of a conditional in (1), the pejorative content of 'wop' survives. Similarly, B's denial is not able to target the pejorative content conveyed by A's question: by uttering 'No, he isn't', B only manages to negate the descriptive content, namely that Jason is Italian, but she does not really interfere with the derogatory content, which survives. The pejorative content of slurs is not easy to assess and if not objected it tends to be imposed on the audience. As Sarah Murray describes: 'not-at-issue [contents] (...) are not negotiable, not directly challengeable, and are added [to the common ground] even if the at-issue proposition is denied' (Murray 2014: 2:9, quoted in Stanley 2015: 135, 158). The point that we want to make is that the fact that the derogatory content of epithets is not-at-issue - fact that Stanley acknowledges - suffices to make slurs propagandistic tools, especially in informal kinds of settings. The fact that they are not the only propagandistic tools provided by language does not make the investigation on slurs any less interesting. Besides, as we note in passing above, their role outside political speech is likely to foster a crucial prerequisite of propaganda - that is, the presence in society of 'beliefs that are resistant to the avail- 
able evidence, [and which] must themselves be flawed in some way' (178). In what follows, we will draw a distinction between slurs and slurs-like terms and we shall suggest that a satisfactory analysis of the former is required in order to understand certain uses of the latter.

Let us now consider the other two points from Stanley: that slurs 'are not special' and that slurs carry a not-at-issue derogatory content. In the literature, scholars who claimed that slurs are not special meant at least two different things. On the one hand, 'slurs are not special' is taken by Geoff Nunberg as a motto that challenges the idea that slurs have a peculiar semantics that lexically encodes derogatory contents, regardless of how this can be achieved (at the level of truthconditions, presuppositions, conventional implicatures, and so on). The kind of approach that Nunberg 2018 suggests, also put forward in different ways by Bolinger 2017 and Rappaport forthcoming, is a deflationary one: nothing in the semantics of slurs encodes negative contents, they only arise conversationally. From this perspective, slurs are just like code words: Nunberg considers the example of 'welfare', whereas Bolinger proposes the example of 'cisgender', a term which refers to people whose gender corresponds to their biological sex, but at the same time affiliates the speaker to the trans community and its allies. 'Cisgender' is a code word in that it is associated with a positive not-at-issue content concerning transgender people. Bolinger, Nunberg and Rappaport describe different pragmatic mechanisms through which certain terms (prototypical slurs, code words like 'welfare', 'cisgender', etc.) get associated with certain contents, but the core of their proposals is that there is nothing in the lexical meaning of these words which encodes additional 'social' contents: '[When a speaker uses the slur 'chink'] you may be able to infer something (...) about what passes for common wisdom about the Chinese in his social circle. But none of that is part of the content of what he said, whether at-issue or not'.

However, this is not the kind of account that Stanley has in mind, as he explicitly favors 'content theories' of slurs (151), according to which the pejorative content of slurs (and the social meaning of other code words) is part of the conventional meaning of the terms. Stanley's interpretation of the motto 'slurs are not special' is that there are plenty of terms that are not slurs but have crucially similar features. Stanley does not embrace their deflationary analysis; on the 
contrary, he holds that slurs and code words lexically encode not-atissue content. We argue that both Stanley's and Nunberg's unified analysis of slurs and code words are problematic, as there seems to be a crucial contrast between slurs like 'wop' or 'kike' and code words like 'welfare' or 'cisgender'. We will show that if one wants to maintain (iii), that slurs lexically encode not-at-issue content, one should drop (ii) and (i) - that there is nothing special about slurs and that, because they just work like any other code term, the attention dedicated to slurs is somehow misplaced. Our point is that, in the case of code words, the associated content is not part of the lexically encoded meaning and therefore it may fail to feature in some occurrences of the term. On the contrary, in the case of slurs, the derogatory content belongs to the lexical meaning of the term and it is conveyed in every literal use of the slur. ${ }^{4}$ If we are right, then it should be possible to use code words literally, without conveying their associated 'social' meaning, while it would not be possible to use slurs literally without conveying their derogatory content. Consider the following examples:

(3) There are no faggots in the army.

(4) Homosexual men are worthy of contempt because of being homosexual.

The occurrence of the homophobic slur 'faggot' in (3) is associated with homophobic contents along the lines of (4) (or maybe Stanley would rather choose something connected to stereotypes, say 'homosexual men are effeminate'). The homophobic content conveyed by the slur 'faggot' cannot be eliminated by stating something that

${ }^{4}$ In this paper we do not assess the issue of appropriation, that could prima facie look like a counterexample of the claim that literal uses of slurs always convey a derogatory content. Even though there is no unanimous account of appropriation, many scholars treat appropriation either (i) as a case of polysemy: therefore an appropriated occurrence of a term like 'fag' would not count as an occurrence of a slurs in the first place (see Ritchie 2017, Jeshion forthcoming.) or (ii) as a case of echoic use of language: therefore, an appropriated occurrence of a term like 'fag' would not count as a literal use of a slur (see Bianchi 2014, Miščević and Perhat 2016, Cepollaro 2017a). We are here assuming that appropriative uses are non-literal ones (but for an account in terms of speech acts, see Anderson forthcoming). Thanks to Dan Zeman for pushing us to clarify this point. 
contradicts its associated derogatory contents, as the offensiveness of (5) and (6) show:

(5) Faggots are not contemptible because of being homosexual.

(6) Faggots are not effeminate.

On the contrary, this associated content can be suspended in the case of code words. Let's consider 'welfare' - taken as an example by Stanley 2015 and Nunberg 2018 — and 'cisgender' — proposed by Bolinger 2017. It is relatively easy to find non-loaded uses of 'welfare', as this example from the COCA (Davies 2008) shows:

(7) Eisenhower took his turn with the interstate highway system and the creation of the department of health, education and welfare.

The codeword 'cisgender' behaves in a similar way. Usually, it is associated with pro-trans-community contents, namely that transgender people have right to respect, full inclusion and equality. However, if it occurs in an utterance that explicitly expresses a transphobic content, the pro-trans-community content usually associated with the code word disappears. As a matter of fact, despite the presence of the codeword 'cisgender', allegedly associated to a positive attitude towards the trans community, (8) is nevertheless transphobic:

(8) Only cisgender people should have the right to adopt children. ${ }^{5}$

We argue that the above examples show that there is a contrast between slurs and other code words in that the former lexically encode what Stanley calls 'social meaning', while the latter do not. In a Bolinger/Nunberg-like framework, one would maintain (ii) — that slurs are not special, they have no exotic or peculiar semantics and work like many other code words - and give up (iii) - that slurs lexically encode not-at-issue content; on the contrary, in a Potts-like perspective, one would maintain (iii) and give up (ii). We think that the examples just provided show a contrast between slurs and code words that speaks in support of the latter option.

In conclusion: we agree with Stanley about implicit messages

${ }^{5}$ Some of these issues, including the contrast between slurs and non-slurring code words, are discussed in Cepollaro 2017b. 
being particularly dangerous and apt to convey pernicious contents in a propagandistic manner. Stanley's analysis of code words like 'welfare' illustrates very well their power and explains why politicians constantly try to come up with terms that could on occasion function like slurs but are not banned from public debate. However, we believe that code words are crucially different from slurs in that the association between the lexical item and an additional social meaning is not as systematic as it is for slurs. In this sense, slurs are special after all and do have a special kind of propagandistic power, even if it typically concerns informal contexts rather than public debates. A satisfactory analysis of prototypical slurs can shed light on the mechanisms at play when non-slurring words are used as slurs.

\section{Positive propaganda}

In this section we will focus on the distinctions introduced by Stanley between different kinds of propaganda. In particular, we are interested in the notion of positive propaganda and its connection to emotional import and effects. We will try to show how positive propaganda need not rely on emotional effects.

The main danger that demagoguery - that is the kind of propagandistic speech Stanley is interested in - poses in liberal societies is to undermine the democratic values that it purports to champion. For Stanley demagoguery does not require insincerity, in that a demagogue can be sincere in his or her effort to attract political support through rhetoric, and it does not require falsity, since the aspect of communication that is responsible for the undermining is typically not part of the truth-functional content - as seen in the previous section with respect to the not-at-issue content of code words and slurs (41). However, demagoguery does require (i) the essential involvement of emotional aspects apt to impinge on rational debate and possibly unify opinions (in line with the classical sense of propaganda, 48), and (ii) the masking of its 'real' goals - that is, demagogic speech looks like supporting an ideal (in particular, reasonableness) while in facts eroding it. For both of those elements - emotional import and masking - to work as gears of the mechanism of propaganda, the presence in society of flawed ideologies is an essential prerequisite, along with their roots in the inequalities that they tend 
to perpetuate. The tight connection between the epistemic deficiencies that flawed ideologies carry along (typically, beliefs resistant to evidence and unjustified connections) and the mechanism of propaganda suggests that propagandistic speech may be wrong per se. However, Stanley rebuts such a 'Kantian' criticism of propaganda as an inherently bad practice, on the ground that an appeal to emotions in public discourse is often indispensable to improve reasonableness in public debate, and hence may be a way to 'address rational will' rather than diminishing it (114). As much as 'negative' propaganda fosters lack of respect towards targeted groups, by indirectly representing them as non-worthy of respect, 'positive' propaganda - that is 'civic rhetoric', in Stanley's terms (82) — enables an emotional manipulation that aims at creating empathy towards minorities, which would be otherwise left out as party to the public debate. Thus, civic rhetoric is a means to implement the ideal of reasonableness in liberal democracy and works in opposition to negative propaganda, which masks itself as encoding the ideal of reasonableness, but actually erodes it by fostering prejudices against targeted groups.

Stanley seems to suggest that 'positive' propaganda is always a form of supporting propaganda, rather than a form of undermining propaganda-i.e., a speech that is presented as an embodiment of certain ideals, and 'tends to increase the realization of those very ideals by either emotional or other nonrational means', rather than a speech that 'tends to erode those very ideals' (53). This is true both of the main theoretical example of civic rhetoric that Stanley makes - Du Bois' theorization of a propagandistic 'Negro art' improving the empathy of whites for Afro-Americans - and of the various examples he takes from contemporary events - such as stark warnings against smoking on cigarettes (58-9), Coltrane's version of My Favorite Things, and the Selma Montgomery March (64, 114). As we have already hinted at, the reason why undermining propaganda is in some sense always at risk of threatening liberal democracies seems to lie in its essential connection with the epistemic deficit that comes with flawed ideologies. The emotional import of propagandistic speech has the effect of cutting off options that should be rationally considered for political deliberation (70), and this may erode rational debate, even when there is a good purpose behind.

Stanley recognizes that supporting propaganda can be flawed, as 
in the case of the representation of the Aryan supremacy in the Nazi regime, or-outside of the political realm and within liberal democracies - as in the case of advertising that exploits a flawed ideology that links material possession with aesthetic worth. However, there seems to be a tension between his claim that positive propaganda is necessary in contemporary liberal democracies, given their imperfect form, and the claim that the core mechanism at play in positive propaganda is still the emotional effect that not-at-issue-content can provide - which potentially can lead to curb rational deliberation. Again, we think that the relevance of discourse outside the political sphere has been pushed too much in the background. Consider the use of 'she' as the default personal pronoun in recent academic (and more at large 'educated') writing. Is there a propagandistic mechanism involved? And is it plausible to construe the not-at-issue content as an emotional element? It seems hard to answer 'no' to the first question. After all, it is a linguistic choice motivated by the will of overcoming a situation of inequality. On the interpretation of the situation we favor, the linguistic use aims at dismantling the fostering of discriminatory stance with respect to women, by creating the expectation that the interlocutor at issue is a woman. If this analysis is on the right track, a typical propagandistic mechanism (by Stanley's own light) is at work here: using 'she' as the default personal pronoun is a way to 'smuggle' a not-at-issue content in the common ground, namely the expectation that the person at stake is a woman. More dubious is to maintain that the not-at-issue content here is emotional, and that its central aim is creating empathy towards the targeted group (women). Our claim is not that this use of 'she' never carries an emotional element of empathy, but only that such an emotional element, if and when present, is not crucial to the rhetorical strategy to be effective. Indeed, the process of updating the conversational common ground seems to happen regardless of any emotional elements which may happen to be associated with the linguistic maneuver. Suppose that a speaker feels hostile emotions towards the elicited expectation that the subject at stake is a woman. ${ }^{6}$

\footnotetext{
${ }^{6}$ This could happen for any reason: say, the speaker supports the anti-discriminatory intention behind the rhetorical use of 'she', but she is displeased by the rhetorical strategy itself, or she just hates to consider women as potential interlocutors.
} 
The use of 'she' as the default personal pronoun succeeds in creating an expectation that the subject at stake is a woman, which is just what it does in ordinary language, despite the emotional effect that it produces in the interlocutor. Empathy with the targeted group is definitely an element that does not disrupt the rhetoric effect, but it is not something in virtue of which the effect of creating the expectation is reached. The expectation is created merely in virtue of how presuppositions ${ }^{7}$ work in ordinary language.

It is worth noting that there are positive and negative forms of discrimination, which are somehow orthogonal to the positive and negative forms of propaganda. Positive forms of discrimination can be supporting, as in the case of affirmative action laws, and can be undermining, or better deterrent, as in the case of a law that prohibits driving for those who do not possess a license (that proves their capability of driving in a safe way for the rest of society). Analogously, negative forms of discrimination can be supporting, as in the case of a selection committee that opts for a candidate for qualities unrelated to the criteria of selection, and they can be deterrent, as in the case of unfairly denying same treatment to an individual because of their gender or race (those are the cases that are more likely to be understood as 'default' discrimination cases, given the ordinary connotations the term bears). Given this taxonomy, the use of 'she' as default pronoun seems to be a rhetorical means to foster positive and supportive discrimination with respect to women. Although the notat-issue content can carry emotional elements, it does not seem plausible to maintain that they are crucial for the linguistic mechanism to work. The systematic use of 'she' as the default pronoun looks like a form of positive supporting propaganda, that, rather than exploiting an emotional effect like in Stanley's examples, has more in common with certain kinds of affirmative action. Consider for instance the so-called 'gender quotas', aimed at increasing women's representation and participation in decision making bodies at executive or legislative levels. This measure constitutes a form of discrimination that is employed (and deemed legitimate at least by the governments that adopt it) in order to counterbalance a state of affairs where women

\footnotetext{
${ }^{7}$ For a presuppositional account of gender features of pronouns, see Cooper 1983 and recently Del Prete and Zucchi 2017.
} 
are severely underrepresented. It would be absolutely unacceptable in a fair society, where sexist ideologies were not widespread. These kinds of initiatives count as positive discrimination (whether they are supporting or not is a matter of debate) and possibly as positive propaganda, but they do not seem to exploit emotional aspects (nor do they impinge on rational debate in this way). In this sense, we find that the systematic use of 'she' in academic writing could well be among the instances of propaganda that interest Stanley, but arguably it would not be analyzed in terms of emotional effects; on the contrary, it closely resembles affirmative action such as gender quotas, discriminatory measures aimed at counterbalancing a pre-existing form of injustice and inequality. Insofar as the creation of a new expectation (i.e., that the interlocutor is a woman) is per se effective in contrasting the discriminatory stances that are associated with the traditional non-egalitarian expectation (i.e., that the interlocutor is a man), we do not have reasons to assume that emotional elements are essentially attached to the rhetorical move.

In conclusion, in this paper we offered a few remarks on two points of Stanely's remarkable book on propaganda. In the first section we argued that code words are crucially different from prototypical slurs and that slurs are special after all, as they do have a special kind of propagandistic power, even if it typically concerns informal contexts rather than public debates. In the second section, we have focused on different kinds of propaganda and considered an instance of positive propaganda that does not seem to rely on the exploitation of emotional mechanisms, namely the systematic use of 'she' as default personal pronoun in academic writing. ${ }^{8}$

Bianca Cepollaro Vita-Salute San Raffaele University, Faculty of Philosophy

${ }^{8}$ We would like to thank Jason Stanley for his replies, Dan Zeman for putting together this symposium, and two anonymous referees for their insightful suggestions. Bianca Cepollaro acknowledges the support of the Labex and Idex grants anr-10-labx-0087 iec, anr-10-idex-0001-02 psl*, project MINECO ffi2012-37658, project PTDC/MHC-FIL/0521/2014 (in particular BI-Mestre-PTDC/MHC-FIL/0521/2014 and PTDC/MHC-FIL/0521/2014SEM). Giuliano Torrengo wishes to thank the project 2015-0746 (15-53007000-601) of Fondazione Cariplo and Regione Lombardia. 
Via Olgettina Milano, 58, 20132 Milan, Italy bianca.cepollaro@gmail.com

Giuliano Torrengo Centre for Philosophy of Time Department of Philosophy "Piero Martinetti", University of Milan Via Festa del Perdono 7, 20122, Milan, Italy giuliano.torrengo@unimi.it

\section{References}

Anderson, L. 2018. Calling, addressing, and appropriation. In Bad Words. Philosophical Perspectives on Slurs, ed. by D. Sosa. Oxford: Oxford University Press, 6-28.

Bach, K. 1994. Conversational impliciture. Mind and Language 9: 124-62.

Bianchi, C. 2014. Slurs and appropriation: an echoic account. Journal of Pragmatics 66: 35-44.

Bolinger, Jorgensen R. 2017. The pragmatics of slurs. Noûs 51(3): 439-462.

Camp, E. 2013. Slurring Perspectives. Analytic Philosophy 54 (3): 330-49.

Carston, R. 2002. Linguistic meaning, communicated meaning and cognitive pragmatics. Mind and Language 17 (1-2): 127-48.

Cepollaro, B. 2017a. When evaluation changes - an echoic account of appropriation and variability. Journal of Pragmatics 117: 29-40.

Cepollaro, B. 2017b. The Semantics and Pragmatics of Slurs and Thick Terms. PhD Dissertation, PSL Research University, Institut Jean Nicod, Paris.

Cepollaro, B. and Stojanovic, I. 2016. Hybrid evaluatives. Grazer Philosophische Studien 93 (3): 458-88.

Cooper, R. 1983. Quantification and Syntactic Theory. Dordrecht: Reidel.

Davies, M. 2008. The Corpus of Contemporary American English: 520 million words, 1990-present, available online athttp://corpus.byu.edu/coca/.

Del Prete, F. and Zucchi, S. 2017. A unified non monstrous semantics for third person pronouns. Semantics and Pragmatics 10. http://dx.doi.org/10.3765/sp.10.10.

Haslanger, S. 2013. Social Meaning and Philosophical Method, APA Presidential Address, handout.

Jeshion, R. forthcoming. Pride and prejudiced. On the reclamation of slurs. Grazer Philosophische Studien.

McCready, E. 2010. Varieties of conventional implicature. Semantics and Pragmatics 3 (8): 1-57.

Miščević, Nenad and Perhat, Julija. 2016. A Word which Bears a Sword. Zagreb, KruZak.

Murray, S. 2014. Varieties of update. Semantics and Pragmatics 7 (2): 1-53.

Nunberg, G. 2018. The social life of slurs. In New Work on Speech Acts, ed. by D. Fogal, D. W. Harris and M. Moss. Oxford: Oxford University Press, 237-295. 
Potts, C. 2005. The Logic of Conventional Implicatures. Oxford, Oxford University Press. Potts, C. 2007. The centrality of expressive indexes. Reply to commentaries. Theoretical Linguistics 33 (2): 255-268.

Rappaport, J. forthcoming. Communicating with slurs. The Philosophical Quarterly. Ritchie, K. 2017. Social identity, indexicality, and the appropriation of slurs. Croatian Journal of Philosophy 17 (2): 155-80.

Sbisà, M. 1999. Ideology and the persuasive use of presupposition. In Language and Ideology. Selected papers from the 6th International Pragmatics Conference, ed. by J. Verschueren: 492-509. Antwerp.

Stanley, J. 2015. How Propaganda Works. Princeton, Princeton University Press. 